\title{
Strategy Transformation Path Choice of Rural Commercial
}

\author{
Banks \\ Pingan Wang \\ Chongqing College Finance and Economics, Chongqing, 402160, China
}

\begin{abstract}
[Abstract] Rural commercial banks stem from rural credit cooperatives. They are important products of rural financial system reform. Since the establishment of system reform, significant achievements have been made. Great contributions have been made to rural economic development in China. Nowadays, original strategy of rural commercial banks cannot adapt fierce competitions of banking development. So, strategy transformation and upgrade have become great realistic problems faced by rural commercial banks. How to adjust and upgrade management strategy has become a focus. This paper proceeds from the reality, discusses strategy transformation path of rural commercial banks and related problems on the basis of relevant literatures and puts forward corresponding suggestions.
\end{abstract}

[Key words] Rural commercial bank; strategy transformation; financial system reform

\section{Introduction}

Currently, some rural credit cooperatives become rural stock commercial banks through system reform in China. According to data statistics of China Banking Regulatory Commission, as of the end of 2013, a total of 590 rural commercial banks had been reformed and opened nationwide (including 468 rural commercial banks and 122 rural cooperative banks). Businesses of rural commercial banks (rural cooperative banks) have occupied a half of the whole country. However, as financial reform and interest rate marketization course accelerate, rural commercial banks encounter unprecedented severe challenges in the aspects of system, mechanism, financial innovation and total risk management. In the new situation, rural commercial banks should speed up transformation development, stably improve competitiveness of rural financial market and achieve sustainable development.

Rural commercial banks from rural credit cooperatives are an important constituent part of Chinese rural financial institutions. Since Zhangjiagang, Changshu ad Jiangyin rural commercial banks were set up, rural commercial banks have gained rapid development in China through development and exploration for many years. But, due to Chinese market capital constraint, acceleration of interest rate marketization and impacts of internet finance, traditional business pattern of banks suffer serious extrusion now. If banks stick to conventions and only earn interest margin, they may encounter worse crisis in the future ${ }^{[1]}$. This forces rural commercial banks to urgently need to change original competitive mode and business pattern. They must adjust and optimize their development strategies again, reposition strategic objectives and change traditional thoughts and direction for bank operation transformation. In this way, they can obtain sustainable competitive advantage and remain invincible in future fierce competitions. 


\section{Analysis of strategy transformation factors and problems of rural commercial banks}

\subsection{External factors}

(1) National economic development and the change in macro-control way have direct influences on operation modes of rural commercial banks, so rural commercial banks need to adapt and support changes in national economic development mode, and autonomously alter the operation modes. In this way, they can grasp more opportunities in economic strategy adjustment ${ }^{[2]}$. Supervision department changes the supervision ways. According to era requirements, China Banking Regulatory Commission puts forward higher standards for four major supervision tools: capital adequacy ratio, leverage ratio, liquidity and dynamic provisioning. This imposes great direct impacts on capital operation, asset expansion, profitability and liquidity of rural commercial banks. (3) Appreciation of money gives rise to huge risks to financial system. Under appreciation of money, financial services of banks gain rapid development. Meanwhile, various risks such as market risk, interest rate risk, information risk and credit risk gradually accumulate and grow. These risks are ignored by rural commercial banks most easily. So, banks' prevention and control ability must be improved to keep alert and prevent possible risks.

(4) Boundary definition of financial development business of banks and non-bank is confused. Under the control of credit scale, credit, insurance, securities and fund cooperate mutually. These non-standard financing operations and instrument innovations emerge in endlessly. This causes financing scale expands continuously. Such innovation cooperation mode scale continuously improves and lengthens financial risk chain, which greatly increases risks of financial system ${ }^{[3]}$. (5) As economic development, personal income and income level boost continuously, many customers' financial management awareness gradually enhances. Traditional financial services cannot meet customers' requirements. Thus, this requires rural commercial banks providing more and more comprehensive financial services to attract more customers. (6) As internet develops and network information level continuously progresses, this promotes emergence of network finance and mobile finance. This directly alters customers' consumption mode and banks' orientation service mode. Network utilizes mass user data to transfer services to such fields as transfer remittance, micro-credit, fund and insurance sales on a commission basis. The above factors are necessary factors of strategy transformation of rural commercial banks.

\subsection{Internal problems}

(1) Business transformation constraint. Rural commercial banks gain stable income through earning interest margin. However, during developing business, business environment is inevitably restricted by social environment, thus leading to business information asymmetry and high business cost. Thus, credit business develops weakly. Transformation power in banks also drops. (2) Traditional profit mode risk. As interest rate market reform, enterprises' demand for credit business becomes smaller and smaller due to the rise in bonds and stick market financing. This greatly impacts traditional operation mode of rural commercial banks. In a long run, unpredictable risks will be caused. (3) Insufficient internal control of banks. Corporate governance still has defects. Due to the existence of principal-agent problem, rights and liabilities of each management layer are chaotic and unclear. It is very hard to reach an effective balance. Meanwhile, due to the defects of management idea, internal control cannot be really established. The channels to gain information are also single. Thus, risk control has serious deficiencies. 


\section{Basic modes of strategy transformation of rural commercial banks}

2.1 Regard nationwide banks as the target, actively reorganize, merge and finally grow into super regional banks

The implementation methods include the following. Firstly, expand bank service scope and actively expand the boundary combining urban and rural areas; secondly, actively trans-regionally purchase branches of original commercial banks, small financial institutions, achieve rational resource allocation and establish powerful brand image; thirdly, exchange and cooperation with the peers and achieve win-win situation; fourthly, set up companies, expand financial leasing business, implement comprehensive operation, carry out linkage cooperation with different industries and trades, expand appreciation space, reduce and spread risks.

2.2 Build brands and establish professional and characteristic bank image

This is a key mode which requires banks detailing each aspect, greatly displaying characteristics, correctly analyzing and positioning market and trying to avoid direct contradictions with banks. Besides, it is required to open up a unique professional service way. Besides, banks must handle the relationship with customers well and give play to relation-based development advantages. This is the key to stabilizing regular customers, attracting new customers and establishing the image of serving customers heart and soul ${ }^{[4]}$.

2.3 Set up the platform for mutual help among small and medium-sized commercial banks

It is necessary to actively communities with adjacent urban and regional banks, establish the win-win cooperation mechanism, construct comprehensive and diversified strategic cooperation planning and finally fulfill resource sharing, cooperation win-win and complementation of mutual advantages ${ }^{[7]}$.

2.4 Build efficient science and technology banks

Banks can combine network information technology to achieve the service of one-point access and whole-city response, construct the win-win, efficient and convenient service platform, plan and innovate new and comprehensive management operational mechanism, collect customers' opinions, improve intelligent service level, promote combination of electronic technique and service and launch brand-new service mode. In this way, sustainable development capacity can improve through the following methods.

\section{Paths for strategy transformation of rural commercial banks}

\subsection{Service object transformation}

(1) Service objects should correspond to small and medium-sized enterprises and individual residents within certain range. This is both an obligation and a responsibility. Meanwhile, this avoids contradictory competitions with large-scale banks and complies with strategy transformation of rural commercial banks. (2) New rural construction promotes rural economic development. The course of city and countryside integration develops unusually rapidly. So, rural commercial banks should implement the ides of "serving agriculture, rural areas and farmers", grasp the opportunity of strategic transformation, combination of urban and rural areas, actively expand business scope and extend regional advantages. (3) It is required to serve carefully, evaluate customers; risk level professionally, study customers and achieve careful services and gain the maximum benefits from every customer.

\subsection{Service concept transformation}

(1) Banks should abide by integration and refinement idea. Integration focuses on payment 
settlement, insurance agency, bills and account management to meet diversified customer demand. Refinement refers to subdividing customer scale, industry and life cycle, displaying characteristic services from customers' perspective and implementing customized services. (2) Banks should establish the idea of individual banks and provide efficient and convenient service of individual residents. In this way, banks can receive more potential customers and easily improve popularity among individual residents so as to establish favorable image ${ }^{[5]}$.

\subsection{Service mode transformation}

(1) Banks should formulate customer grades, carry out differential treatment for high-grade customers, make targeted services, launch interest rate policy and link with customers' comprehensive benefit. In this way, if customers' deposits and related businesses are more, customers will enjoy larger credit interest rate range. Besides, this can enhance customers' loyalty index. This successfully drives deposits and relevant business development. (2) Banks also should optimize deposit and withdrawal forms and meets the needs of some customers who have different withdrawal time, but want to gain the income higher than demand deposit interest rate. Meanwhile, it is required to change single loan mode, create guaranty way, carry out a series of new pledge modes, innovate financing modes and develop bill financing and supply chain financing etc.

\subsection{Business structure transformation}

(1) Banks should develop towards low-capital occupation-based business pattern, transform basic concept, alter capital occupation type, business pattern and dependence on wholesale credit business, and strive to develop low-capital occupation-based businesses ${ }^{[6]}$. (2) It is also required to adjust customer structure, enrich resources brought by customers, drive comprehensive operation layout, further expand it, gain breakthroughs in a series of key fields such as securities and insurance, continuously boost customer structure adjustment, realize equal development of big customers and small customers and reach the purpose of enriching customer resources. (3) Banks also need to boost channel construction, conclude electronic construction and financial services in the same service platform, form an organic whole, and complement each other so as to reach full play to functions of different channels and provide equal services for customers in different channels ${ }^{[7]}$.

\subsection{Profit mode transformation}

(1) It is necessary to optimize profit modes, follow up multiple product services, regard wholesale business as the initiator of multiple businesses, and retain customer relationship through wholesale business so as to gain follow-up intermediate business income. Meanwhile, banks should strive to reduce cost of wholesale business and drive other business with high benefits. (2) Banks should pay attention to retail banking business. Retail banking business is characterized by many types, quick changes and heavy residential consumption. So, it can easily facilitate new product demand. Besides, it is relatively stable in terms of business income and profit. Therefore, retail industry may become the highlight of profit mode transformation. (3) For intermediate business, it is necessary to gain success through quality. It is required to start from investment bank, financial management and trusteeship for intermediate business. These can become sustainable growth power of non-interest income. Besides, bank card, e-bank and personal financial management own strong customer resources. Channel building can be conducted further to enhance dependence of common customers on banks; convenient and fast services.

3.6 Internal management system transformation

Power and responsibility boundary among each management layer should be specified. 
Efficient and strict supervisory mechanism should be constructed. Each management layer should perform its own functions. Meanwhile, performance appraisal system should be performed. The evaluation standard should be established for customer service to practically improve operation performance and external service level ${ }^{[8]}$.

\section{Conclusions}

To sum up, strategy transformation of rural commercial banks is a complex strategic project. It is necessary to stick to scientific development perspective and specify banks' development target and path. Innovative changes should be mainly made in such aspects as service object, service concept, service mode, business structure, profit mode and management system. Meanwhile, talent introduction and training should be strengthened. Scientific and technical guarantee and support should be promoted. Good management idea should be confirmed. After achieving these, rural commercial banks will certainly gain powerful development and become an important component of Chinese rural financial market.

\section{[References]}

[1] Wang Wei, Performance evaluation of trans-regional management of Chinese rural commercial banks [J]. Journal of Guangdong University of Business Studies. 2013(06)

[2] Wang Wei, Current situation, influencing factors and performance evaluation of trans-regional management of Chinese rural commercial banks [J]. Financial Theory \& Practice, 2013(12)

[3] Zhang Yufang, Study on operation efficiency and reform path of Chinese rural new financial organizations [J]. Wuhan Finance Monthly, 2013(12)

[4] Yi Mianyang, Chen Jian, Introspection of development path and system of Chinese rural credit cooperatives [J]. Researches in Chinese Economic History, 2011(02)

[5] Huang Dajun, Thoughts and countermeasures on management innovation of rural commercial banks [J]. Money China (Academic Version), 2010(09)

[6] Tang Shengjiang, Discussion on operation and management modes of rural commercial banks [J]. Money China (Academic Version), 2010(09)

[7] Wang Tianhua, Discussion on risk control of rural commercial banks [J]. Modern Economic Information, 2010(14)

[8] Li Bihui, Liu Zongjie, Qi meifu, Chen Hongyu and Ma Xianxian, Problems in rural bank reform and development and suggestions - case study of Anhui Province [J]. Financial Supervision, 2010(12) 